\title{
Comparative Study on Mechanical Properties of V-Shaped Insulator String under Fluctuating and Calm Wind
}

\author{
J.J. Huang, X.M. Chen, Y. Xiong \\ State Grid Hubei Electric Power Research Institute \\ Wuhan Hubei 430077, China
}

\author{
C.L. Liu \\ China Electric Power Research Institute \\ Beijing 100055, China
}

\author{
Y. Wang \\ Beijing Guowang Fuda Science \& Technology Development Co., Ltd \\ Beijing 100070, China
}

\begin{abstract}
In order to define mechanical properties of $\mathrm{V}$-shaped insulator strings under dynamic wind load, a numerical commutating method is adopted. By carrying out comparative analysis of dynamic and static calculation results, this paper provides a theoretical basis for engineering design.
\end{abstract}

Keywords-v-shaped insulator; mechanical analysis; calm wind; buckling

\section{INTRODUCTION}

With the rapid development of national economy of China, the electricity demand of the entire society has greatly increased. Since most energy bases in China are located at western part, the optimal configuration [1] of energy resources has to be realized on a national scale through electricity transmission from the west to the east of China, the north and the south power exchange and nationwide interconnection. A number of built power lines in China have to cross high-wind areas, so the $\mathrm{V}$-shaped insulator string is adopted to improve windage yaw of insulators so as to reduce insulator windage yaw of the straight-line tower. The current design specification calculates mechanical properties of the $\mathrm{V}$-shaped insulator string as per static wind load and then multiplies the security coefficient. In order to define mechanical properties of $\mathrm{V}$-shaped insulator strings under dynamic wind load, it is necessary to carry out comparative study on mechanical properties of $\mathrm{V}$-shaped insulator strings under fluctuating and calm wind.

\section{THEORETICAL BASIS OF CALCULATION}

Literature [2, 3] deduced fundamental formulas such as catenary balance equation and created an iterative algorithm. On this basis, Literature $[4,5]$ deduced a catenary element stiffness matrix with a finite element method, which was used to analyze planar and spatial structure of suspension cables. The basic motion equation of dynamics is as follows:

$$
M \ddot{u}+C \dot{u}+K u=F .
$$

where, $M$ is structural mass matrix, $K$ is stiffness matrix, $C$ is damping matrix, $\ddot{u}$ is acceleration vector, $\dot{u}$ is velocity vector, $u$ is displacement vector, and $F$ is load vector.

The motion balance equation is a second-order linear ordinary differential equation system with constant coefficients, which can be in theory solved with a typical method for ordinary differential equation systems. Two numerical solutions are generally adopted during actual finite element dynamic analysis, i.e. modal superposition method and immediate integration [6].

\section{CALCULATION OF WIND LOAD}

A wind time-history curve generally contains two components: one is long-period part whose value is always above $10 \mathrm{~min}$; the other is short-period part whose value is often only several seconds. The fluctuating wind is caused by wind irregularity, whose intensity changes over time as per randomness rules; since its period is short, it has a dynamic function and vibration may be caused. We adopt the down-wind horizontal fluctuating wind velocity spectrum used in Chinese specifications, which is a Davenport spectrum. Thus, the fluctuating wind velocity time history under high wind conditions is obtained through calculation.

The lateral wind load produced by wind action on conductors should take into account influences of shape factor of conductors, wind-pressure uneven factor related to wind velocity, wind-load adjustment factor related to voltage level and wind velocity, wind velocity-height change factor related to average height of conductors, angle between wind direction and conductor axial direction, etc. The wind load on unit length of conductors should be calculated by formula (2) according to standards of the power industry in China.

$$
g_{H}=0.625 \times \alpha \times \mu_{s c} \times(d+2 \delta) \times\left(K_{h} \times v\right)^{2} \times 10^{-3}
$$


where, $\alpha$ is uneven factor of conductor wind pressure, $\mu_{\text {sc }}$ is shape factor of conductor, $d$ is outside diameter (mm) of conductor, $\delta$ is thickness (mm) of conductor icing, $K_{h}$ is wind velocity-height change factor at the average height $h$ of

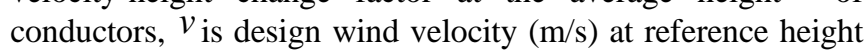
$h_{s}$ of lines.

The wind load on bundled conductors is specified in IEC60826 Code for Design of Overhead Transmission Line that as follows [7]: the wind load on bundled conductors is the number of bundles multiplying wind load of a single conductor, with shielding effect of bundled conductors neglected.

\section{NumERICAL CALCULATION MODEL}

The conductor is a flexible structure, and the geometric nonlinear problems about big displacement and small deformation should be considered during analysis. At the same time, the initial static balance position of conductor system constitutes an initial condition of static and dynamic analysis, which is of great significance for results of calculation. Therefore, we should firstly carry out static balance analysis on the conductor system, and then establish a calculation model according to assembly drawing of insulator strings.

Conduct windage yaw analysis on the insulator-hardware fitting-conductor system under calm and high wind conditions. Select horizontal span of $500 \mathrm{~m}$ and vertical span of $500 \mathrm{~m}$, with a difference of $0 \mathrm{~m}$. The length of the entire composite insulator string should be $11.0 \mathrm{~m}$ and the model of V-shaped insulator strings is shown in Figure 1 . A conductor of $6 \times \mathrm{JL} / \mathrm{G} 3 \mathrm{~A}-1000 / 45-72 / 7$ is adopted for mechanical calculation. The starting calculation height of reference wind velocity should be $10 \mathrm{~m}$ and the category of ground roughness is regarded as Category B. The design basic wind velocity is $33 \mathrm{~m} / \mathrm{s}$ (at $10 \mathrm{~m}$ height), the average height of conductors is regarded as $30 \mathrm{~m}$, and the wind velocity here is converted into $39.34 \mathrm{~m} / \mathrm{s}$.

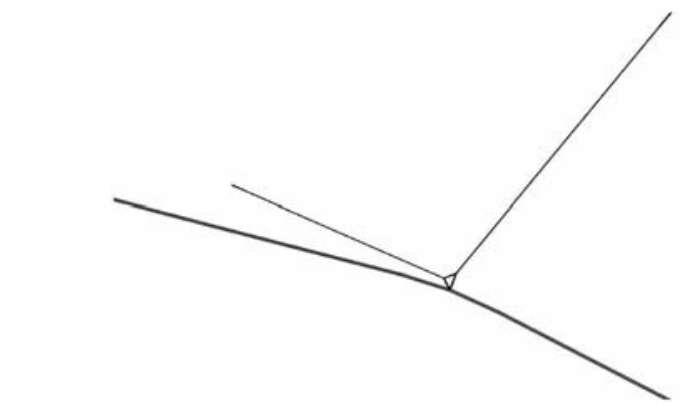

FIGURE I. NUMERICAL CALCULATION MODEL OF V-SHAPED INSULATOR STRING.

\section{STATICS CALCULATION OF V-Shaped INSUlATOR STRING}

When there is only one $\mathrm{V}$-string with included angle of $100^{\circ}$, the force imposed on single-string insulators at windward side of $\mathrm{V}$-string under calm wind is $148.94 \mathrm{kN}$ and that imposed on such insulators at its leeward side is $-0.08 \mathrm{kN}$.
When there is only one V-string with included angle of $110^{\circ}$, the force imposed on single-string insulators at windward side of $\mathrm{V}$-string under calm wind is $151.27 \mathrm{kN}$ and that imposed on such insulators at its leeward side is $7.01 \mathrm{kN}$.

When there is only one V-string with included angle of $120^{\circ}$, the force imposed on single-string insulators at windward side of $\mathrm{V}$-string under calm wind is $159.03 \mathrm{kN}$ and that imposed on such insulators at its leeward side is $22.57 \mathrm{kN}$.

\section{Mechanical Properties of INSUlator StRING UndeR FLUCTUATING WIND}

Under high and fluctuating wind conditions, we calculate mechanical properties of $\mathrm{V}$-string at fluctuating wind. After buckling deformation is caused on the insulators at leeward side under fluctuating wind, the deformation of V-shaped insulator string is shown in Figure 2.

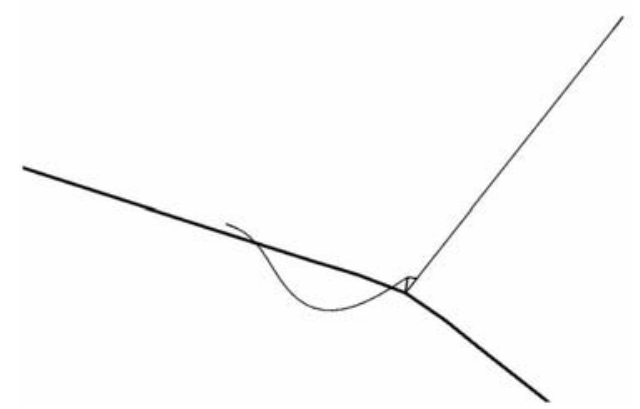

FIGURE II. BUCKLING DEFORMATION OF V-SHAPED INSULATOR STRING UNDER HIGH WIND.

\section{A. Calculation Results When There Is Only One V-String with Included Angle of 100}

The force time-history curve of single-string insulators at windward side of $\mathrm{V}$-string under fluctuating wind is shown in Figure 3, and the maximum value is $256.21 \mathrm{kN}$ which is 1.72 times of static calculation value.

The force time-history curve of single-string insulators at leeward side of $\mathrm{V}$-string under fluctuating wind is shown in Figure 4 , and the maximum value is $87.35 \mathrm{kN}$. The insulators have buckling deformation.

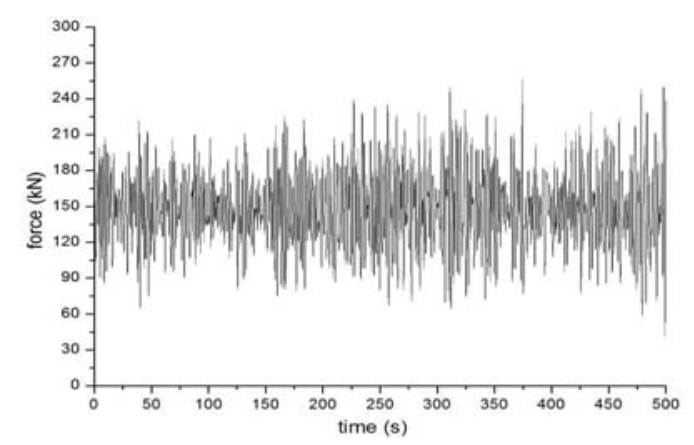

FIGURE III. FORCE TIME-HISTORY CURVE OF SINGLE-STRING INSULATORS AT WINDWARD SIDE OF V-STRING. 


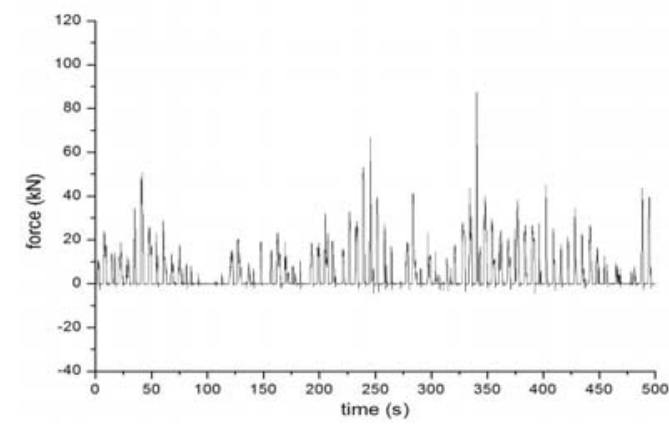

FIGURE IV. FORCE TIME-HISTORY CURVE OF SINGLE-STRING INSULATORS AT LEEWARD SIDE OF V-STRING.

B. Calculation Results When There Is Only One V-String with Included Angle of $110^{\circ}$

The force time-history curve of single-string insulators at windward side of V-string under fluctuating wind is shown in Figure 5, and the maximum value is $252.81 \mathrm{kN}$ which is 1.67 times of static calculation value.

The force time-history curve of single-string insulators at leeward side of $\mathrm{V}$-string under fluctuating wind is shown in Figure 6, and the maximum value is $81.31 \mathrm{kN}$. The insulators have buckling deformation.

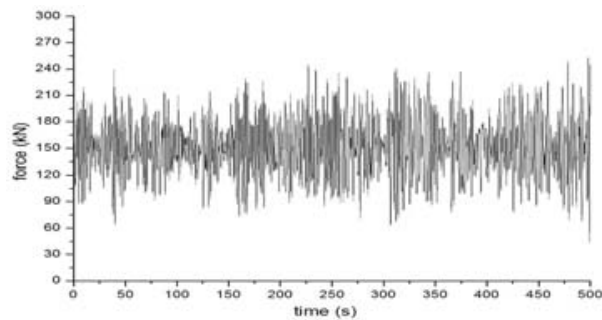

FIGURE V. FORCE TIME-HISTORY CURVE OF SINGLE-STRING INSULATORS AT WINDWARD SIDE OF V-STRING.

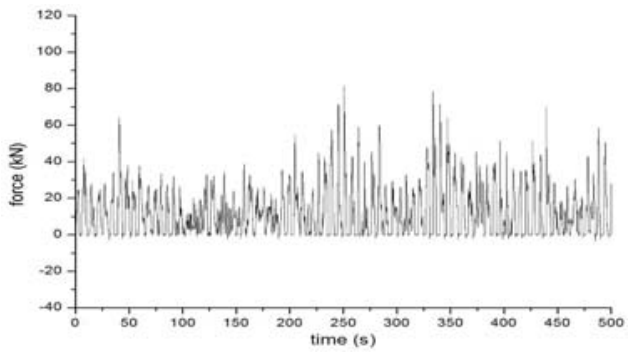

FIGURE VI. FORCE TIME-HISTORY CURVE OF SINGLE-STRING INSULATORS AT LEEWARD SIDE OF V-STRING.

\section{Calculation Results When There Is Only One V-String with} Included Angle of $120^{\circ}$

The force time-history curve of single-string insulators at windward side of $\mathrm{V}$-string under fluctuating wind is shown in Figure 7, and the maximum value is $269.12 \mathrm{kN}$ which is 1.69 times of static calculation value.

The force time-history curve of single-string insulators at leeward side of V-string under fluctuating wind is shown in
Figure 8, and the maximum value is $98.02 \mathrm{kN}$. The insulators have buckling deformation.

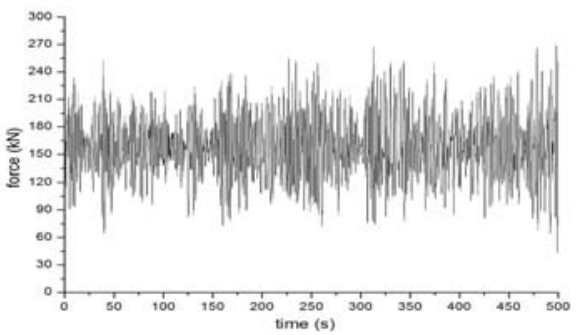

FIGURE VII. FORCE TIME-HISTORY CURVE OF SINGLE-STRING INSULATORS AT WINDWARD SIDE OF V-STRING.

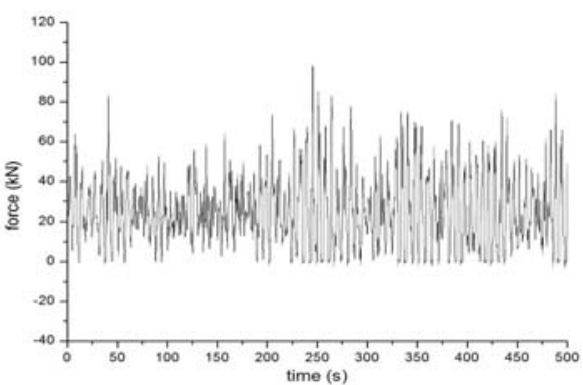

FIGURE VIII. FORCE TIME-HISTORY CURVE OF SINGLE-STRING INSULATORS AT LEEWARD SIDE OF V-STRING.

\section{SUMMARY}

The following conclusions are obtained according to calculation results.

The numerical calculation can effectively simulate the force-receiving process of $\mathrm{V}$-shaped insulators under calm and fluctuating wind, and corresponding mechanical properties are obtained.

The maximum value of forces on single-string insulators at leeward side of $\mathrm{V}$-string under fluctuating wind is about 1.7 times of the force imposed under calm wind.

The dynamic response of insulators cannot be reflected under calm wind. However, the dynamic calculation under fluctuating wind can reflect buckling deformation of insulators.

\section{REFERENCES}

[1] Z.Y. Liu, Ultra-high voltage power grid[M]. Beijing: China Economic Publishing House, 2005.

[2] W. Terence, O. Brien, A. J. Francis, Cable movements under two dimensional loads [J]. Journal of the Structural Division, ASCE, 1964(90):89-123.

[3] W. Terence, O. Brien, General solution of suspended cable problems [J]. Journal of the structure Division Engineering, ASCE, 1967, 93(1):1-26.

[4] H. M. Irvine. Cable structures [M].The MIT Press.1981.

[5] A. Peyrot, J. Lee, H. Jensen, J. Osteraas, Application of cable elements concept to a transmission line with cross rope suspension structures [J]. IEEE transactions on power apparatus and systems. 1981, 7(100):3254-3262.

[6] X.T. Zhang, Z.P. Wang, B.C. Huang. Mechanics of Structural Vibration [M]. Shanghai: Tongji University Press, 1994.

[7] Design Criteria of Overhead Transmission Lines (IEC60826) [S].2003. 